\title{
A culinária caipira da paulistânia - A disputa pelo GOSTO DA COZINHA CAIPIRA65
}

\author{
Daniel Coelho de OLIVEIRA*
}

Em certa ocasião, o sociólogo alemão Norbert Elias (2001) disse que levantar o véu das mitologias que mascaram a sociedade era parte do seu ofício profissional. Seguindo a mesma trilha, na obra intitulada A culinária caipira da Paulistânia, editada em 2018, o sociólogo Carlos Alberto Dória e o cozinheiro Marcelo Corrêa Bastos articulam fontes históricas, literárias e culinárias para um panorama da cozinha caipira brasileira. Também metem a colher em temas tidos como verdades, ao questionar, por exemplo, o mito da cozinha mineira. Vale destacar que o aspecto provocador da obra levantou grande debate em espaços não acadêmicos ${ }^{66}$.

Numa perspectiva quase arqueológica, os autores procuram vestígios do que seria a região da Paulistânia, espaço geográfico que correspondia à Capitania de São Paulo, no momento da sua criação, ou seja, a culinária no interior dos estados de Minas Gerais, São Paulo, Goiás e Paraná. Sendo que a pouca quantidade de registros

\footnotetext{
${ }^{65}$ Resenha da obra: DÓRIA, Carlos Alberto; BASTOS, Marcelo Corrêa. A culinária caipira da Paulistânia a história e as receitas de um modo antigo de comer. São Paulo: Três Estrelas, 2018. 368p

* UNIMONTES - Universidade Estadual de Montes Claros. Departamento de Ciências Sociais. Programa de Pós-Graduação em Sociedade, Ambiente e Território. Montes Claros - MG - Brasil. 39401-089 daniel.coelhoo@yahoo.com.br.https://orcid.org/0000-0003-2565-6551.

${ }^{66}$ Seguem as reportagens consideradas relevantes sobre o livro: Histórias e receitas da cozinha caipira são foco de livro de sociólogo com chef escrita por Alex Bessas (2019), Porque este especialista diz que a 'culinária mineira é um mito de Ana Paula Boni (2018), Polêmica à Mesa: Pesquisadores questionam originalidade da comida mineira de Luiza Fecarotta (2018) e Obra faz investigação quase arqueológica da cozinha paulista de João Fellet (2018).
} 
dessa culinária foi uma das dificuldades enfrentadas pelos autores. Sua invisibilidade do ponto de vista do registro de cultura imaterial de alguma maneira também representa o lugar que o caipira ocupa na historiografia brasileira. Afinal, o que define o caipira? Para Ribeiro (1995), seria aquele que não encontrou sentido na vida, ou que não tem uma raça definida. Candido (2010) aponta que o caipira foi descendente duma mistura do branco com índio, o caboclo, que não se adaptou às formas mais produtivas e intensas de trabalho. Em geral vivia da caça, possuía dificuldades para se nutrir, negou o enquadramento do salário e do patrão, da mesma maneira que o modelo de trabalho servil não conseguiu enquadrá-lo. Por sua vez, Monteiro Lobato (1994) foi responsável pela produção da imagem caricaturada de tal indivíduo, através do emblemático Jeca Tatu.

Com bastante perícia, os autores de A culinária caipira da Paulistânia constroem argumentos na complexa tarefa de caracterizar a cozinha caipira. A definição, segundo os mesmos, deveria ir além do amontoado de pratos que usualmente identificam tal tradição. Esse posicionamento já foi explorado por Dória (2014), ao alertar que não conhecíamos a cozinha brasileira. Para ele, a definição do que seria nossa cozinha é feita através de alguns pratos que exemplificam o que ela é. Faltaria um conceito consistente que unifique a coleção de receitas e não limite as respostas aos simples exercício de exemplificação. Responder à questão pelo caminho da miscigenação de etnias africanas com povos europeus, em especial os portugueses, e a contribuição indígena, trata-se de uma explicação confortável, mas é um conceito que carece de poder explicativo.

Os autores acreditam ainda que o conceito de Paulistânia representa, com certa exatidão, o espaço e o tempo de formação do que entendemos hoje por culinária caipira. Ao definir a especificidade culinária da Paulistânia, eles reforçam a ideia de que a mesma foi resultado do percurso que vai dos primórdios do século XVI, na capitania de São Vicente, e chega até o início do século XIX. Entretanto o termo Paulistânia só se fixou graças à historiografia de cunho conservador, provinciano de intelectuais paulistas. A palavra teria ganhado destaque no contexto do movimento constitucionalista dos paulistas.

Ocorreram alterações na ocupação da Paulistânia, pois, se no primeiro momento a ênfase foi na apropriação territorial e submissão das populações indígenas, no segundo destaca-se a lógica de produção familiar, presentes na agricultura de subsistência e materializadas principalmente na figura do sítio. Este sendo visto pelos autores como espaço privilegiado, do ponto de vista histórico e metodológico, bem como espaço que materializava as relações sociais mais gerais da cozinha caipira. 
Dória e Bastos (2018) propõem um aprofundamento sobre a variedade produtiva que compunham o sítio. Destaca-se, para tanto, o trato do milho, o feijão, produtos que junto com a abóbora formam o tripé vegetal da cozinha caipira. Acrescentam-se a esses elementos básicos o arroz, a mandioca e a banha de porco. Este último ocupou importante papel na economia brasileira, em 1895, por exemplo, chegou a ser o principal produto importado dos Estados Unidos, mesmo com intensas campanhas de desqualificação para uso culinário e questionamentos sanitários. Além da banha, a manteiga perdeu espaço, por justificativas semelhantes.

De certa forma, a sociedade caipira foi vista por grande parte da Paulistânia como rurais, atrasadas, em oposição ao dinamismo urbano que surgia; retardatária em contrataste com a cultura moderna que se americanizava. A partir dos anos de 1950, em especial no estado de São Paulo, a culinária daquela foi jogada para debaixo da mesa, preterida em relação à comida industrializada e pelos novos hábitos dos imigrantes europeus. Nos relatos do general Couto de Magalhães, por exemplo, foi possível observar o distanciamento entre a comida popular e a elite da cidade de São Paulo. Na visão dos autores, ao longo do tempo a elite paulista foi se afrancesando.

$\mathrm{Na}$ segunda parte do livro a cozinha caipira é contada através dos seus ingredientes e modos de feitura. São apresentas as características da mesa relacionada a ela no século XX. Para isso, foi realizado o que os autores denominam de voo rasante sobre as receitas da mesma. Com destaque para o que se comia no desjejum, os cozidos, as caças, o milho, o arroz, as conservas, os refogados, os mexidos, as farofas e paçocas, as frituras, as empatadas, tortas, pães e roscas. Todas as receitas apresentadas podem propiciar, segundo os autores, uma oportunidade de refletir sobre o próprio sistema de classificação dos pratos da tradição brasileira. O sistema francês, por exemplo, não se adequaria à nossa realidade. Os ritmos das refeições não são os mesmos e a própria originalidade local torna os pratos inclassificáveis. Os leitores ainda são alertados que, ao logo do período de formação da culinária caipira, alterações aconteceram, como na maneira de comer dos mais antigos, e as próprias matérias-primas, utensílios e técnicas mudaram profundamente.

O pano de fundo da obra seria o confronto entre questões de formação do Estado Nação e o regionalismo da cozinha mineira. Ao que tudo indica, essa diversidade de identidades teria sido forjada através do contato com a terra, com os alimentos, a tradição e a cultura alimentar. A relação entre a formação da nacionalidade brasileira e a nossa cozinha brasileira pode ser resgatada em autores como: Sérgio Buarque, Gilberto Freyre e Caio Prado Jr., Câmara Cascudo, bem como no movimento modernista da primeira metade dos anos 1920, período que, segundo os autores, começa a falar em cozinha brasileira, no sentido atual, após a impregnação de 
toda a cultura pelas ideias que nasceram da revisão do ser brasileiro, como fez o movimento modernista na primeira metade dos anos 1920, ou mesmo o movimento regionalista de 1930 no Nordeste. Dória (2014) já havia destacado a emergência do tema cozinhas regionais, a partir de 1920, de maneira mais consistente através das migrações a partir de 1930, quando as questões culinárias regionais, por seu turno, ganham concretude nos grandes centros especialmente a partir do movimento modernista e seu contraponto nordestino, o movimento intelectual liderado por Gilberto Freyre.

A construção de uma cozinha mineira unificada encobre um conjunto de diversidades existentes no próprio estado, como destaca a tese de Costa (2003), onde existiriam no mínimo dois diferentes territórios em Minas Gerais. A região das Minas, marcada pela herança da mineração, e os Gerais, terra catrumana, com diversidade culinária, com uma história ainda pouco contada, não mais do que descrito nos romances de Guimarães Rosa. Os autores destacam que a maior parte das obras sobre a culinária mineira se concentram em análise da região das minas, como o livro Mineiridade: ensaio de caracterização, do arquiteto e historiador mineiro Sylvio de Vasconcelos (1968).

A Paulistânia, conceito que demarcado pelo território de alcance dos bandeirantes paulistas, talvez não consiga representar a diversidade culinária caipira, ou seja, o mundo caipira é maior do que o espaço da Paulistânia. Aceitar essa definição também seria o mesmo que defender a influência dos bandeirantes como maior indutor da comida caipira. Como o livro bem exemplifica, outros condicionantes tiveram um papel importante, como a cultura indígena guarani, ou o apogeu e declínio na mineração nas Minas Gerais, em Cuiabá, e da própria matriz portuguesa. Talvez a comida caipira não seja da região das Minas, como todo seu ideal de mineiridade, mas não pode ser classificada como da Paulistânia, até por que as características da alimentação caipira estão muito além das duas demarcações espaciais.

O resultado da classificação baseada no território da Paulistânia seria um mapa marcado por continuidades e descontinuidades espaciais. Criaria assim, o que Dória e Bastos (2018) denominam de regionalismo culinário, bastante útil na competição por espaços políticos, sendo que todos estariam dotados de certa personalidade singular. É bem clara a crítica realizada pelos autores ao regionalismo culinário, mas ao final seria possível visualizar uma proposta que substitui o regionalismo pelo macrorregionalista da cozinha da Paulistânia.

Mesmo com a descrição do consumo na cidade de São Paulo e o processo de surgimento das feiras e do Mercado Municipal, a obra A culinária caipira da 
Paulistânia pouco explora a dimensão desses espaços na formação da identidade caipira. O sítio e os bairros rurais podem até ser o vértice do desenvolvimento da culinária caipira, mas o espaço de exposição por excelência dessa culinária são as feiras livres, mercados municipais e os calendários de festas públicas. Sendo possível destacar as festas de Santos Reis, festas juninas de Santo Antônio, São João e São Pedro, além de uma infinidade de quermesses do interior.

Dória e Bastos (2018) apontam ainda que existe a construção de uma narrativa falaciosa sobre a formação da culinária mineira de que o mito da cozinha mineira foi construído alicerçado em uma ideia de cozinha do passado, reafirmada como cozinha típica através de campanhas publicitárias, obras literárias, discursos políticos e memorialistas. Apropriando-se assim, de elementos que na verdade caracterizariam a comida caipira da Paulistânia.

Assim como os autores, Abdala (2012) destaca a existência de uma cozinha mineira imaginária e ideológica, cada vez mais reencantada com a nostalgia do passado. A construção do mito da mineiridade, de glória, passa pela produção de um imaginário coletivo da mesa típica da região Minas. Ou seja, a cozinha mineira foi um mito construído no decorrer de alguns séculos.

O argumento central aparece no final da obra: "No final das contas, não existe diferença notável entre a cozinha mineira e a tradicional paulista, a ponto de justificar a classificação distinta. O que parece existir, sim, são atitudes diferentes de mineiros e paulistas diante da culinária caipira" (DÓRIA \& BASTOS, 2018, p.300). Os autores reconhecerem a diferença de atitude dos mineiros, em relação aos paulistas, quando o assunto é tradição culinária caipira ao destacarem que os primeiros a adotam como patrimônio, passado apreciado, enquanto os paulistas, de maneira especial os paulistanos, a tem como comida desprezível, de pobre, pré-moderna. A resposta para superação da tipificação regional brasileira estaria em uma nova forma de classificação, como foi apontado na conclusão: "consideramos a comida mineira como parte integrante da grande tradição culinária caipira da Paulistânia" (DÓRIA \& BASTOS, 2018, p.300). A proposta dos autores que procura uma nova paulistanidade que negaria a imagem construída através da mítica do bandeirante, deveria passar pela revisão do próprio recorte geográfico da nossa historiografia, caso contrário, estaríamos substituindo um mito por outro.

Estaria em jogo a disputa pelo espólio da culinária caipira? O testamento da cozinha caipira certamente explicitaria que ela extrapolou territorialmente a região historicamente definida com Paulistânia. Mesmo que sua caracterização prevalecesse nesse recorte geográfico, sua diversidade é tão grande que dificilmente poderia ser enquadrada somente como cozinha mineira, Paulistânia, ou caipira. Seria razoável, 
portanto, falar em cozinhas caipira mineira, cozinhas caipira paulista, cozinhas caipira goiana, assim por diante. Nesse caso o plural não é apenas um detalhe.

\section{Referências}

ABDALA, Mônica Chaves. Ressignificação do tradicional e o típico mineiro. COLLAÇO, Janine. et. al. Dimensões socioculturais da alimentação: dialógicos latino-americanos. Porto Alegre: Editora da UFRGS, 2012.

BESSAS, Alex. Polêmica à Mesa: Pesquisadores questionam originalidade da comida mineira. O Tempo. Publicado em 13 de janeiro de 2019. Disponível em: <https://www.otempo.com.br/gastro/pesquisadores-questionam-originalidade-dacomida-mineira-1.2090099>. Acessado em: 31 out. 2019.

BONI, Ana Paula. Histórias e receitas da cozinha caipira são foco de livro de sociólogo com chef. O Estado de São Paulo. Publicado em 03 de outubro de 2018. Disponível em: <https://paladar.estadao.com.br/noticias/comida,historias-e-receitasda-cozinha-caipira-sao-foco-de-livro-de-sociologo-com-chef,70002531165>. Acessado em: 31 out. 2019.

CANDIDO, Antonio. Os Parceiros do Rio Bonito: estudo sobre o caipira paulista e a transformação dos seus meios de vida. Rio de Janeiro: Ouro sobre Azul, 2010.

COSTA, João Batista de Almeida. Mineiros e Baianeiros: Englobamento, Exclusão e Resistência. Tese de Doutorado Brasília: Universidade de Brasília, 2003.

DÓRIA, Carlos Alberto. Formação da culinária brasileira. São Paulo: Três Estrelas, 2014.

DÓRIA, Carlos Alberto; BASTOS, Marcelo Corrêa. A culinária caipira da Paulistânia - a história e as receitas de um modo antigo de comer. São Paulo: Três Estrelas, 2018.

ELIAS, Norbert. Norbert Elias por ele mesmo. Rio de Janeiro: Zahar, 2001.

FECAROTTA, Luiza. Obra faz investigação quase arqueológica da cozinha paulista. Folha de São Paulo. Publicado em 14 de outubro de 2018. Disponível em: 
<https://www1.folha.uol.com.br/ilustrada/2018/10/obra-faz-investigacao-quasearqueologica-da-cozinha-paulista.shtml>. Acessado em: 31 out. 2019.

FELLET, João. Porque este especialista diz que a 'culinária mineira é um mito'. BBC News Brasil. Publicado em 08 de dezembro de 2018. Disponível em:

<https://www.bbc.com/portuguese/brasil-46403816>. Acessado em: 31 out. 2019.

LOBATO, Monteiro. Urupês. 37. ed. São Paulo: Brasiliense, 1994.

RIBEIRO, Darcy. O povo brasileiro: formação e o sentido do Brasil. São Paulo: Companhia das Letras, 1995.

VASCONCELOS, Sylvio. Mineiridade: ensaio de caracterização. Belo Horizonte: Imprensa Oficial, 1968.

Recebido em 01/03/2019.

Aprovado em 29/09/2019. 